\title{
Influence of Corrosive-Aggression Medium on the Residual Resource of Annular Wheel of Steam Turbine under Variable Loads
}

\author{
Olexandr Andreikiv, Valentyn Skalskyi, Iryna Dolinska \\ Karpenko Physico-Mechanical Institute of National Academy of Sciences of Ukraine, 5 Naukova Street, Lviv \\ 79601, Ukraine \\ *Corresponding Author: Olexandr Andreikiv, Karpenko Physico-Mechanical Institute of National \\ Academy of Sciences of Ukraine, 5 Naukova Street, Lviv 79601, Ukraine
}

\begin{abstract}
A method for determination of the residual resource of annular wheel of steam turbine with a corrosion-fatigue crack is proposed. The influence of corrosive medium on its residual life-time is estimated. The corrosive medium decreases the residual durability of the disk more than twice.
\end{abstract}

Keywords: corrosion medium, corrosion-fatigue crack, fatigue crack, annular wheel of steam turbine, residual resource.

Abbreviations: $\beta, \eta \quad$ characteristics of kinetics diagram of growth of corrosive-fatigue crack in materials which experimentally measured, $\rho$ density, $\mu$ Poisson's ratio, $\omega$ angular velocity, $h$ thickness of disk, $l_{0}$ initial length of crack, $l_{*} \quad$ critical size of crack, $N$ number of loading cycles, $N_{*} \quad$ residual recourse, $K_{I}$ stress intensity factor, $K_{f C}, K_{s c c}, K_{t h}$ critical and threshold values stress intensity factor, $R$ stress ratio, $r_{l}, r_{2}$, inner and outer radii of disk

\section{INTRODUCTION}

It is known [1-4] that corrosive media intensify the fracture of metallic materials under long-term loads (static or cyclic) and lead to the propagation of corrosion-fatigue cracks. For the determination of the residual life-time of structural elements under these conditions, it is necessary to have the corresponding estimation models. The majority of the known models [1-4] are based only on specific experimental results. By using these results, it is possible to determine the residual recourse only for some structural elements with certain materials. The influence of corrosive media on the fracture of power-generating equipment elements is studied insufficiently, in particular a wheels of steam turbines. In the present work, the estimation model is constructed and accordingly method for evaluation of influence of corrosive media on the residual life-time of wheels of steam turbines under the action cyclic load.

\section{FORMULATION OF THE ESTIMATION MODEL}

Consider a flat disk (annular) of steam turbine with inner and outer radii $r_{1}$ and $r_{2}$, respectively, constant thickness, and density $\rho$. The disk rotates with an angular velocity $\omega$ (Fig. 1). Assume that the disk has a surface crack of length $l$ and is loaded by cyclic tension and is subjected to the action of corrosive-aggressive medium. The problem is to determine the residual recourse of the disk $t=t_{*}$ (the number of loading cycles $N=N_{*}$ ) for which the crack grows to the critical size $l=l_{*}$ after which the disk fails. We solve the posed problem by using the energy approach formulated earlier [5]. On the basis of the mathematical model from [6,7], the period $N=N *$ of subcritical growth of the crack under the conditions of fatigue and corrosive-aggressive medium in thin-walled structural elements, will be determined from equation (1) under the initial and final conditions (2)

$$
\frac{d l}{d N}=\beta \frac{\left.(1-R)^{4}\left[K_{\mathrm{I}}^{2}(l)-K_{s c c}^{2}\right)\right]^{2}+\eta\left[K_{\mathrm{I}}^{2}(l)-K_{s c c}^{2}\right]}{\left[K_{f C}^{2}-K_{\mathrm{I}}^{2}(l)\right]}
$$




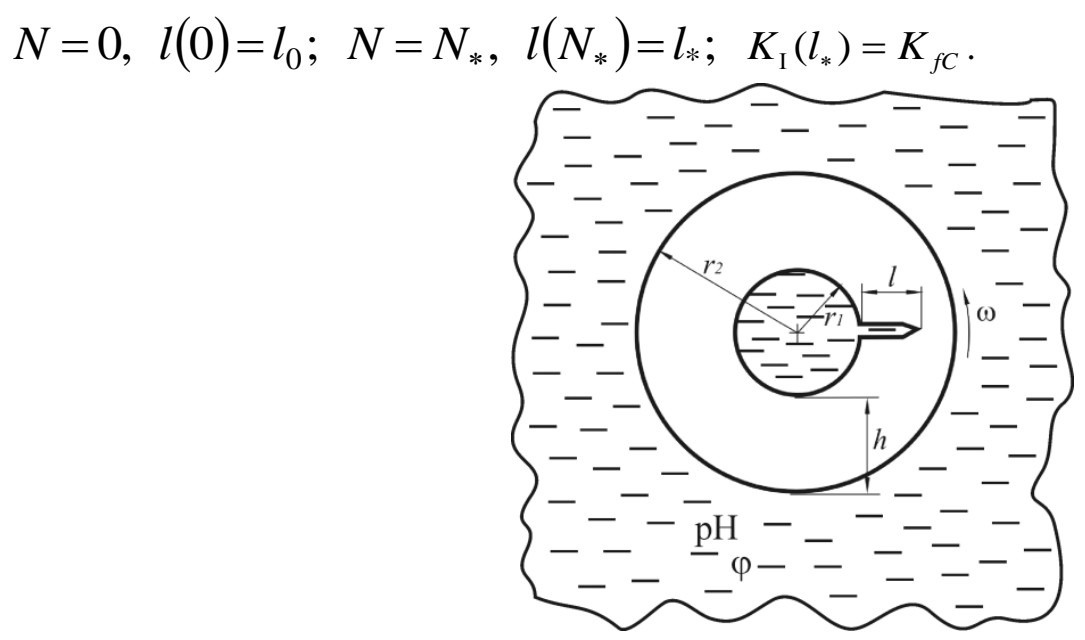

Fig1. Annular disk of a steam turbine in corrosive media ( $\varphi$ is galvanic potential)

Here, $K_{\mathrm{I}}$ is the stress intensity factor (SIF) near the crack tip, $K_{f C}$ and $K_{s c c}$ are critical and threshold values SIF, $\beta$ and $\eta$ are characteristics of kinetics diagram of growth of corrosive-fatigue crack in materials which experimentally measured $[6,7], R$ is the stress ratio, $l_{0}$ is initial length of crack, $l_{*}$ is critical size of crack.

To evaluate the effect of a corrosive medium on the life-time of a disk, we first consider the problem without the action of the corrosive medium. Then, the disk will be fracture only by the propagation of the fatigue crack. In this case, in Eq. (1) should be put $\eta=0$. Then we obtain an equation for determining the kinetics of the fatigue crack propagation

$$
\frac{d l}{d N}=\frac{\left.\beta(1-R)^{4}\left[K_{\mathrm{I}}^{2}(l)-K_{t h}^{2}\right)\right]^{2}}{\left[K_{f C}^{2}-K_{\mathrm{I}}^{2}(l)\right]}
$$

With the following initial and final conditions

$$
N=0, l(0)=l_{0} ; N=N_{*}, l\left(N_{*}\right)=l_{*} ; \quad K_{\mathrm{I}}\left(l_{*}\right)=K_{f C} .
$$

Where $K_{t h}$ is threshold values SIF when there is no corrosive medium.

By using the results obtained in [8], we represent the unknown quantity $K_{\mathrm{I}}$ from relation (1) in the form

$$
K_{I}=0.25 \sqrt{\pi l} \rho \omega^{2}\left[(3+\mu) r_{2}^{2}+(1-\mu) r_{1}^{2}\right] F(\varepsilon, \lambda),
$$

Where $\mu$ is Poisson's ratio,

$$
\begin{aligned}
& F(\varepsilon, \lambda)=\frac{1.1215 \sqrt{1-\varepsilon}}{\sqrt{1+0.8460 \varepsilon}}\left\{1+\sqrt[4]{\frac{1.3333\left[(2+\lambda)^{2}-1-\lambda\right]}{(1-\varepsilon)\left[(3+\mu)(1+\lambda)^{2}+(1-\mu)\right.}}-\right. \\
& \left.-\sqrt[4]{\frac{1.3333\left[(2+\lambda)^{2}-1-\lambda\right]}{\left[(3+\mu)(1+\lambda)^{2}+(1-\mu)\right.}}\right\}^{4} \\
& \lambda=h r_{1}^{-1}, \varepsilon=l h^{-1} \text {. }
\end{aligned}
$$

As in [8], to simplify the numerical solution, we consider the case $\lambda=1$. In this case, relation (5) takes the form

$$
K_{I}=0.25 \sqrt{\pi l} \rho \omega^{2} r_{1}^{2}[4(3+\mu)+1-\mu] \cdot \frac{1.1215 \sqrt{1-\varepsilon}}{\sqrt{1+0.8460 \varepsilon}}\left(0.0948+\frac{0.9052}{\sqrt[4]{1-\varepsilon}}\right)^{4} .
$$




\section{Evaluation of the AnNular Disk Resource}

We now determine the residual number of cycles to fracture of a turbine wheel with 12KhMFA steel [2]. By using the diagrams of growth of fatigue cracks [2], we take the following characteristics of the material and the parameters of loading: $K_{f C}=80 \mathrm{MPa} \sqrt{\mathrm{m}}, K_{t h}=12 \mathrm{MPa} \sqrt{\mathrm{m}}$, $\beta=3,2 \cdot 10^{-9}, h=r_{1}=0.3 \mathrm{~m}, \omega=50 \mathrm{~s}^{-1}, R=0$. Thus, in view of relation (6), we reduce Eq. (3) to the following approximate form:

$$
\frac{d l}{d N}=3.2 \cdot 10^{-9} \frac{\left(2.4 \cdot 10^{5} l B-144\right)^{2}}{6.4 \cdot 10^{3}-2.4 \cdot 10^{5} l B}
$$

with the following initial and final conditions

$$
N=0, \quad l(0)=l_{0} ; \quad N=N_{*}, \quad l\left(N_{*}\right)=l_{*} ; \quad K_{\mathrm{I}}\left(l_{*}\right)=K_{f C}
$$

where

$$
B=(1-3.3 l)\left(0.0948+\frac{0.9052}{\sqrt[4]{1-3.3 l}}\right)^{4}(1+2.8 l)^{-1}
$$

We find the numerical solution of the estimation model (7), (8) and construct the dependence $N_{*} \sim l_{0}$ (Fig. 2, curve 1). It is easy to see that the residual number of cycles to fracture of the turbine wheel $N_{*}$ decreases as the size of the initial fatigue crack $l_{0}$ increases.

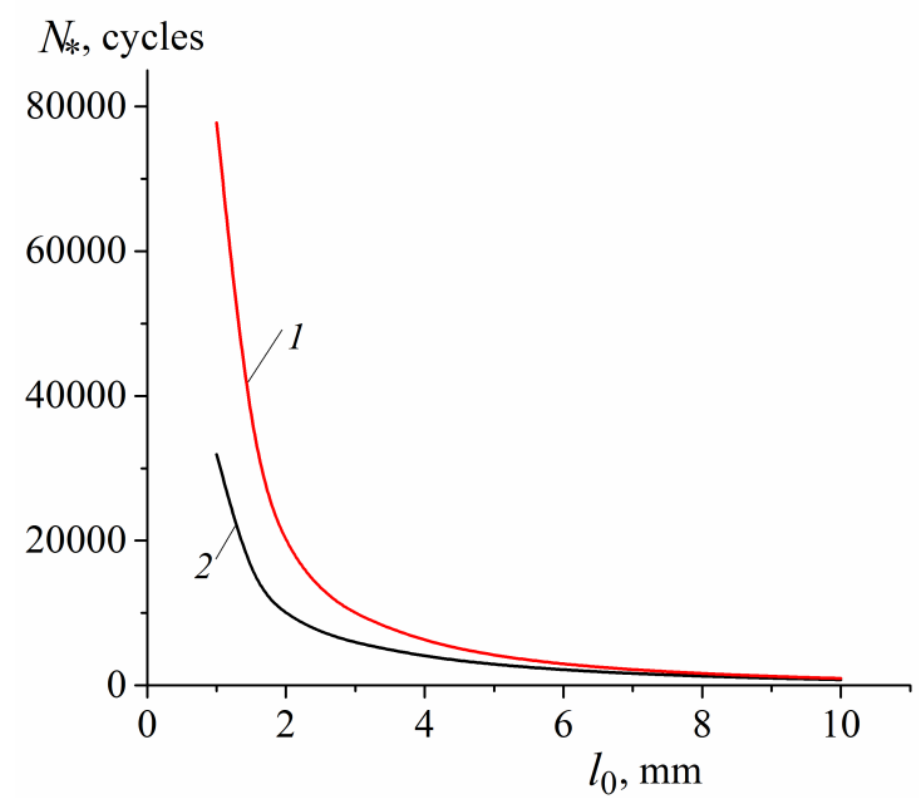

Fig2. Dependence of residual number of cycles to fracture $N_{*}$ of disk on the initial crack size $l_{0}$ : curve 2 in a corrosion medium, curve 1 without the action of the corrosive medium.

Later we will evaluate the influence of the corrosive medium on the life-time of a disc with a fatigue crack. To do this, we apply the calculation model (1), (2). Integrating Eq. (1) under conditions (2), we obtain the following formula for the determination of residual recourse of the annular disk under the action cyclic load and corrosive medium:

$$
N_{*}=\int_{l_{0}}^{l_{*}} \frac{\left[K_{f C}^{2}-K_{\mathrm{I}}^{2}(l)\right] d l}{\left.\beta\left\{(1-R)^{4}\left[K_{\mathrm{I}}^{2}(l)-K_{s c c}^{2}\right)\right]^{2}+\eta\left[K_{\mathrm{I}}^{2}(l)-K_{s c c}^{2}\right]\right\}} .
$$


By using the diagrams of growth of corrosive-fatigue cracks [2], we take the following characteristics of the material and the parameters of loading: $K_{f C}=80 \mathrm{MPa} \sqrt{\mathrm{m}}, K_{s c c}=15 \mathrm{MPa} \sqrt{\mathrm{m}}$, $\beta=3,2 \cdot 10^{-9}, \eta_{2}=925, h=r_{1}=0.3 \mathrm{~m}, \omega=50 \mathrm{~s}^{-1}, R=0$. For a calculation we will substitute these characteristics and parameters into formula (9). The integral in (9) is taken numerically. As a result, we construct the dependence of $N_{*} \sim l_{0}$ (Fig. 2, curve 2). We see that corrosive medium decreases the period of subcritical growth of fatigue cracks in the annular disk (the residual resource of annular disk) more than twice.

\section{CONCLusions}

The estimation model is constructed for the evaluation of the period of subcritical growth of corrosive-fatigue cracks in the wheel of steam turbines. The residual resource is computed for the annular wheel.

Influence of corrosive medium on the durability of disk: corrosive medium decreases the residual durability of the disk more than twice.

\section{REFERENCES}

[1] Panasyuk V.V. (editor), Fracture Mechanics and Strength of Materials: A Handbook [in Russian], Vol. 4: Romaniv O N., Yarema S.Ya., Nikiforchin G.N., Makhutov N.A., and Stadnik M.M., Fatigue and Cyclic Crack Resistance of Structural Materials [in Russian], Naukova Dumka, Kiev (1990).

[2] Dmytrakh I.M., Panasyuk V.V., Influence of Corrosive Media on the Local Fracture of Metals Near Stress Concentrators [in Ukrainian], Physicomechanical Institute, Lviv (1999).

[3] Arnoux P., Atomistic simulations of stress corrosion cracking, Corrosion Science, 2010, 52, pp. 12471257.

[4] Sieradzki K., Newman R.C., Stress-corrosion cracking, J. Phys. Chem. Solids, 1987, Vol. 48, No 11, pp. 101-113.

[5] Banahevych Yu.V., Andreykiv O.E., Kit M.B., Prediction of residual pipeline resource taking into account the operation loading conditions, Strength of Materials, 2009, Vol. 41, No 1, pp. 32-38.

[6] Popovich P., Tson O., Dovbush T., Impact of operation medium on the propagation of the surface corrosion fatigue cracks in the agricultural mashines structural elements, Bulletin of TNTU, 2014, Vol. 75, No 3, pp. 157-166.

[7] Andreikiv O.Ye., Dolinska I.Ya., Lysyk A.R., Growth of corrosion crack in two-layer plates under longterm loads, Conference Proceedings, Int. Conference "In-service damage of materials, its diagnostics and prediction", pp. 173-176 (2017).

[8] Andreikiv O.E., Sas N.B., Evaluation of the period of subcritical growth of a high-temperature creep crack in the wheel of a steam turbine, Materials Science, 2010, Vol. 46, No 3, pp. 297-306.

\section{AUTHORS' BIOGRAPHY}

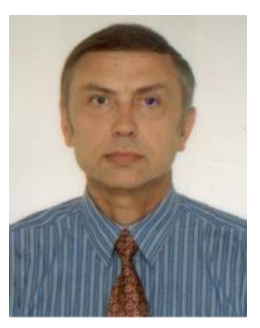

Olexandr Andreikiv, is DSc and Professor in the Department of Mechanics (Faculty of Mechanics and Mathematics) of Ivan Franko National University of Lviv. He is Member Corresponding of the National Academy Sciences of Ukraine

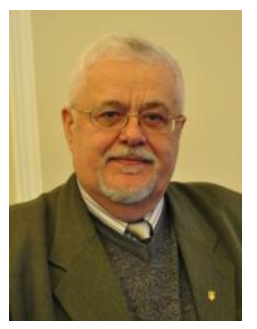

Valentyn Skalskyi, is DSc and Professor and Deputy Director for Science of the Karpenko Physico-Mechanical Institute of the National Academics Sciences of Ukraine. He is Member Corresponding of the National Academy Sciences of Ukraine. 
Influence of Corrosive-Aggression Medium on the Residual Resource of Annular Wheel of Steam Turbine under Variable Loads

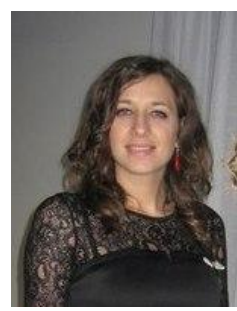

Iryna Dolinska, is $\mathrm{PhD}$ and Senior Researcher of Department of Acoustic Methods of Technical Diagnostics of the Karpenko Physico-Mechanical Institute of the National Academy Sciences of Ukraine.

Citation: Olexandr Andreikiv et al, (2017). Influence of Corrosive-Aggression Medium on the Residual Resource of Annular Wheel of Steam Turbine under Variable Loads, International Journal of Modern Studies in Mechanical Engineering (IJMSME), 3(4), pp.39-43, DOI: http://dx.doi.org/10.20431/24549711.0304005.

Copyright: (C) 2017 Olexandr Andreikiv. This is an open-access article distributed under the terms of the Creative Commons Attribution License, which permits unrestricted use, distribution, and reproduction in any medium, provided the original author and source are credited 